\title{
One-step synthesis of gene carrier via gamma irradiation and its application in tumor gene therapy
}

This article was published in the following Dove Press journal: International Journal of Nanomedicine

\author{
Sung In Jeongl,* \\ Seong-Cheol Park $2, *$ \\ Sun-Jeong Park $2, *$ \\ Eun-Ji Kim ${ }^{2}$ \\ Hun $\mathrm{Heo}^{2}$ \\ Jong-Seok Park' \\ Hui-Jeong Gwon' \\ Youn-Mook Lim' \\ Mi-Kyeong Jang ${ }^{2}$
}

'Research Division for Industry and Environment, Advanced Radiation Technology Institute, Korea Atomic Energy Research Institute, Jeongeup, ${ }^{2}$ Department of Polymer Science and Engineering, College of Engineering, Sunchon National University,

Suncheon, Korea

*These authors contributed equally to this work

\begin{abstract}
Introduction: Although numerous studies have been conducted with the aim of developing drug-delivery systems, chemically synthesized gene carriers have shown limited applications in the biomedical fields due to several problems, such as low-grafting yields, undesirable reactions, difficulties in controlling the reactions, and high-cost production owing to multi-step manufacturing processes.
\end{abstract}

Materials and methods: We developed a 1-step synthesis process to produce 2-aminoethyl methacrylate-grafted water-soluble chitosan (AEMA-g-WSC) as a gene carrier, using gamma irradiation for simultaneous synthesis and sterilization, but no catalysts or photoinitiators. We analyzed the AEMA graft site on WSC using 2-dimensional nuclear magnetic resonance spectroscopy (2D NMR; ${ }^{1} \mathrm{H}$ and ${ }^{13} \mathrm{C}$ NMR), and assayed gene transfection effects in vitro and in vivo. Results: We revealed selective grafting of AEMA onto C6-OH groups of WSC. AEMA-g-WSC effectively condensed plasmid DNA to form polyplexes in the size range of 170 to $282 \mathrm{~nm}$. AEMA-g-WSC polyplexes in combination with psi-hBCL2 (a vector expressing short hairpin RNA against $B C L 2$ mRNA) inhibited tumor cell proliferation and tumor growth in vitro and in vivo, respectively, by inducing apoptosis.

Conclusion: The simple grafting process mediated via gamma irradiation is a promising method for synthesizing gene carriers.

Keywords: water-soluble chitosan, 2-aminoethyl methacrylate, gamma irradiation, gene delivery

\section{Introduction}

Chitosan is a product derived from chitin deacetylation, which is the most abundant natural biopolymer present in the cell walls of some fungi and the exoskeletons of crustacean shells. ${ }^{1-4}$ It is a promising biomaterial with many applications in various biomedical fields such as gene delivery, wound healing, tissue engineering and repair, industrial area containment, agriculture, food science, water treatment, cosmetics, and the paper industry. ${ }^{2,5-8}$ Due to its biocompatibility, biodegradability, low cytotoxicity, and high cationic-charge density, chitosan has been reported to be a good candidate for gene delivery of non-viral vectors. ${ }^{9}{ }^{10}$ However, pure chitosan/DNA polyplexes have shown poor gene-transfection efficiencies in practical applications due to low intracellular trafficking abilities related to poor cell binding and uptake, endosomal escape, and polyplex dissociation. ${ }^{11}$

Grafting or modifying the various side chains of chitosan is crucial for increasing the grafting percentage and efficiency and for expanding the applicability of chitosan for gene delivery. ${ }^{12}$ Gene carrying is a critical factor for safe and efficient gene-delivery systems, and much work is being done in this area. ${ }^{13}$ Copolymers used in gene delivery have 
been mostly synthesized using chemical agents. ${ }^{14}$ Methods for grafting functional groups (such as carboxyl groups, an amine group, imidazole groups, disulfide linkage, and $\mathrm{pH}$-sensitive linkages) onto natural polysaccharides are important techniques for developing advanced materials. Although chemical grafting methods that use ethyl (dimethylaminopropyl) carbodiimide, dicyclohexylcarbodiimide, 4-dimethylaminopyridine, and N-hydroxysuccinimide have been widely used, they have disadvantages such as a complicated purification processes, low yields, and the formation of side products. Moreover, unremoved reactants or side products can have adverse effects due to toxicity in the body. ${ }^{15}$ Recently, several advantages have been described for grafting or crosslinking methods employing radiation processes. ${ }^{16-18}$ Products resulting from these processes are free from impurities due to the lack of catalysts and additives in the initial reaction. In addition, the degree of grafting can be easily controlled by the radiation dose. ${ }^{19,20}$ Chemical-free grafting methods (high-energy radiation including microwaves, $\mathrm{UV}$ and/or gamma rays, and electron beams) have been used to produce safe and highly efficiency products. ${ }^{21-23}$ Among them, gamma-ray irradiation shows the most potential for synthesizing grafted copolymers, given its simplicity, high-energy emission, non-thermal process, and lower cost. ${ }^{24}$ Moreover, the Joint FAO/IAEA/WHO Expert Committee on Food Irradiation (JECFI) declared in 1997 that foods irradiated with up to $10 \mathrm{kGy}$ are safe and nutritionally adequate for evaluating the toxicological, nutritional, chemical, and physical aspects of foods. ${ }^{25}$

A previous study performed to test the grafting of various types of acrylate monomers onto chitin and chitosan using radiation via initiator systems showed that the grafting yield increased in a dose-dependent manner. ${ }^{26}$ For example, Yilmaz et al reported the radiation-dependent grafting of chitosan with N, N-dimethyl aminoethyl methacrylate. ${ }^{27}$ Yu et al showed that the increase in grafting percentage depended on an increased concentration of starting materials, the total gamma-irradiation radiation dose, and the reaction temperature for graft polymerization of butyl acrylate onto chitosan. ${ }^{28}$ Casimiro et al developed a biocompatible and microbiologically safe wound-dressing membrane prepared by gammairradiation polymerization of chitosan and hydroxyethyl methacrylate. ${ }^{29}$ The acrylate monomer was activated by irradiation due to the breakdown of the double bond of the vinyl group. The activated monomer could graft other moieties, including hydroxyl groups. However, these systems often require cytotoxic initiators and additional chemical-grafting steps. $^{29}$ In this study, we developed a novel 2-aminoethyl methacrylate-grafted chitosan vector, whose positive net charge was increased via a radiation reaction without toxic initiators. The vector has great potential for guiding genetransfection behavior in gene-delivery applications.

\section{Materials and methods Materials}

Chitosan, 2-aminoethyl methacrylate (AEMA), and $\mathrm{D}_{2} \mathrm{O}$ were purchased from Sigma Aldrich Co. (St Louis, MO, USA). DMEM, Roswell Park Memorial Institute (RPMI1640) medium, PBS, and fetal bovine serum (FBS) were obtained from Bio-West (Logan, UT, USA). Trypsin-EDTA was purchased from Gibco ${ }^{\circledR}$ (Thermo Fisher Scientific, Waltham, MA, USA). The pEGFP-N1 plasmid was obtained from Clontech Laboratories, Inc. (Palo Alto, CA, USA).

\section{Preparation of the AEMA-grafted water-soluble chitosan (AEMA-g-WSC) copolymer}

The protocols for preparing and fractionating WSC are described elsewhere. ${ }^{30}$ Gamma irradiation was used to graft AEMA to WSC. First, $0.6 \mathrm{mmol}$ of WSC and $0.06 \mathrm{mmol}$ of AEMA were dissolved in $4 \mathrm{~mL}$ deionized water and $1 \mathrm{~mL}$ methanol, respectively. The WSC and AEMA solutions were mixed in a vial, and the AEMA-WSC solution was irradiated with gamma rays at a 5,10 , or $25 \mathrm{kGy}$ dose using a ${ }^{60} \mathrm{Co}$ source (MDS Nordion, Canada, IR $221 \mathrm{n}$ wet storage type C-188, KAERI, Daejeon, Korea). The AEMA-WSC solution was dialyzed using a dialysis membrane in distilled water for $48 \mathrm{~h}$, followed by freeze-drying.

\section{NMR analysis of the AEMA-g-WSC copolymer}

The ${ }^{1} \mathrm{H}_{-}{ }^{13} \mathrm{C}$ heteronuclear single-quantum correlation (HSQC) spectrum of AEMA-g-WSC was determined in $\mathrm{D}_{2} \mathrm{O}$ solution using a Bruker Avance-500 FT-NMR Spectrometer (Bruker Biospin, Rheinstetten, Germany).

\section{DNA electrophoretic mobility shift assay experiments}

Five hundred nanograms each of pEGFP-N1 were complexed with AEMA, WSC, or AEMA-g-WSC at various w/w ratios. The polyplexes were run in a $0.7 \%(\mathrm{w} / \mathrm{v})$ agarose gel stained with GelRed ${ }^{\mathrm{TM}}$ Nucleic Acid Stain solution (KOMA BIOTECH Co., Seoul, Korea) and visualized on a UV transilluminator using a gel-documentation system (Bio-Rad Laboratories, Hercules, CA, USA).

\section{Particle size and zeta potential of complexes with plasmid DNA}

After the pEGFP-N1/AEMA, WSC, and AEMA-g-WSC complexes were incubated for $30 \mathrm{~min}$ at room temperature, 
$250 \mu \mathrm{L}$ of PBS was further added. The particle sizes and zeta potentials of polyplexes were measured using a dynamic-light scattering (DLS) instrument (ELS-8000; Otsuka Electronics, Osaka, Japan), fitted with a He-Ne laser at a fixed scattering angle of $90^{\circ}$.

\section{In vitro cell viability and hemolysis assays}

The mouse fibroblast L929 cell line was obtained from the Korean Cell Line Bank (KCLB 10001, Seoul National University, Seoul, Korea). The cells were maintained in DMEM supplemented with $10 \% \mathrm{FBS}$ and an antibiotic-antimycotic mixture (Thermo Fisher Scientific) for $24 \mathrm{~h}$ at $37^{\circ} \mathrm{C}$ in $5 \% \mathrm{CO}_{2}$. They were seeded at a density of $5 \times 10^{3}$ cells/well in a 96-well plate and incubated overnight. AEMA, WSC, and AEMA-g-WSC were then introduced into the cells. After $48 \mathrm{~h}, 10 \mu \mathrm{L}$ of cell counting kit-8 (CCK-8; Sigma-Aldrich Co.) solution was added to each well. The optical density was measured at $450 \mathrm{~nm}$. Negative control cells were treated with $0.1 \%$ Triton X-100.

Blood was obtained from healthy rats through cardiac puncture using a syringe and was transferred to a heparin tube. Collected fresh rat red blood cells (rRBCs) were washed in PBS until the supernatant was clear. Serial 2-fold dilutions of samples in PBS were added to 96-well plates, and rRBCs were then added to a final concentration of $8 \%(\mathrm{v} / \mathrm{v})$, after which the plates were incubated with mild agitation for $1 \mathrm{~h}$ at $37^{\circ} \mathrm{C}$. The plates were then centrifuged at $1,000 \times g$ for $10 \mathrm{~min}$ and the absorbance of the collected supernatants was measured at $414 \mathrm{~nm}$; each measurement was taken in triplicate and the negative control consisted of cells treated with $0.1 \%$ Triton $\mathrm{X}-100$.

\section{Transfection of plasmid DNA/polymers}

Human HCT116 colon cancer cells which were obtained from the KCLB were seeded at a density of $5 \times 10^{4}$ cells/well in a 24-well plate. The cells were grown in RPMI-1640 medium supplemented with $10 \% \mathrm{FBS}$ and $1 \%$ antibiotic-antimycotic for $24 \mathrm{~h}$ at $37^{\circ} \mathrm{C}$ in $5 \% \mathrm{CO}_{2}$. After an overnight preincubation, pEGFP-N1/polymer complexes in antibiotic-free RPMI-1640 in the presence of serum were transfected at the indicated $\mathrm{w} / \mathrm{w}$ ratios. After $24 \mathrm{~h}$, the cells were observed under a fluorescence microscope.

To investigate the intracellular uptake of polyplexes, AEMA-WSC was labeled with the fluorescent dye FNR675 (BioActs, Incheon, Korea). HCT119 cells were seeded in 6-well plates at $2 \times 10^{6}$ cells/well and incubated overnight before the assay. After treatment with the pEGFP-N1/AEMAg-WSC complexes for $6 \mathrm{~h}$, the cells were washed with PBS, harvested, and FNR-675 fluorescence was analyzed.

\section{In vitro antitumor activity}

HCT116 cells were seeded into a 96-well plate at a density of $5 \times 10^{3}$ cells/well and incubated for $24 \mathrm{~h}$. The WSC, AEMA, or AEMA-g-WSC samples were complexed with the indicated concentrations of psi-hBCL2 (which expresses short hairpin RNA [shRNA] against BCL2 mRNA) in a $20 \mu \mathrm{L}$ of Dulbecco's PBS. The polyplex solutions were added to culture medium containing $10 \% \mathrm{FBS}$, and the plate was incubated for $48 \mathrm{~h}$ at $37^{\circ} \mathrm{C}$. The antitumor activity of polyplexes with pDNA (psi-hBCL2) was evaluated in a CCK-8 assay.

HCT116 cells were transfected with psi-hBCL2 and untreated cells were collected by centrifugation, after which Bcl-2 protein expression was quantified by immunofluorescence staining and flow cytometry. Briefly, cells were fixed in $4 \%$ paraformaldehyde and permeabilized in PBS containing $0.1 \%$ Triton $\mathrm{X}-100$ and $1 \%$ albumin for $4 \mathrm{~min}$, to which mouse antihuman Bcl-2 (1:100) was incubated for $1 \mathrm{~h}$ and washed three times with PBS containing 1\% albumin, followed by adding a DyLight ${ }^{\circledR} 650$-conjugated goat antimouse secondary Ab IgG (1:300). After 30 min incubation, the cells were washed three times with PBS containing $1 \%$ albumin and detached from plate. Cells were analyzed quantitatively using an Attune NxT acoustic focusing cytometer (Thermo Fisher Scientific).

\section{In vivo antitumor effects of polyplexes}

In vivo animal studies were approved by the Animal Care Committee of Korea Atomic Energy Research Institute (KAERI-IACUC-2016-030), and all animal care was performed in accordance with the guidelines of the Korea Council on Animal Care. HCT116 xenografts were prepared using 5-week-old female BALB/c-nu mice (15 $\pm 2 \mathrm{~g}$ ) obtained from Orient Bio, Inc. (Seongnam, Korea). The mice were housed at 2-3 animals/cage under conditions of controlled temperature $\left(22^{\circ} \mathrm{C} \pm 2{ }^{\circ} \mathrm{C}\right)$, humidity $(55 \% \pm 15 \%)$, and lighting (illuminance of 150-300 Lux). To generate xenografts, $1 \times 10^{7} \mathrm{HCT} 119$ cells $/ \mathrm{mL}$ suspended in $200 \mu \mathrm{L}$ of 1:1 (v/v) PBS/Matrigel (Becton Dickinson Biosciences, Franklin Lakes, NJ, USA) were injected into the flanks of the mice. After injecting the tumor cells, the subcutaneous tumor volume $(V)$ was measured with digital calipers and calculated using the formula $V=\left(a b^{2}\right) / 2$, where $a$ is the biggest orthogonal tumor diameter and $b$ is the smallest. When the tumor diameters reached 4-6 $\mathrm{mm}$, the indicated polyplex samples were delivered by subcutaneous injection into the tumor masses. The tumor size was monitored daily for 20 days. Histological observations were performed by $\mathrm{H} \& \mathrm{E}$ and immunohistochemical staining, according to standard procedures. 


\section{Statistical analysis}

All data are presented as the mean \pm SE. Statistical analysis of the results was performed by running a Student's $t$-test.

\section{Results and discussion}

Recent reports have shown that low-molecular weight chitosan can improve the transfection efficiency of genedelivery vectors, ${ }^{31-34}$ thus, we used WSC with a low molecular weight of $5.5 \mathrm{kDa}$ for radiation grafting with AEMA. AEMA-g-WSC was synthesized by irradiation with dosages of 5, 10, or $25 \mathrm{kGy}$. Previous research suggested disadvantages of converting the high-molecular weight chitosan into chito-oligosaccharides via gamma irradiation, such as browning and a decreased solubility and molecular weight of chitosan..$^{35,36} \mathrm{We}$ analyzed the molecular weight and polydispersity index (PDI) of gamma-irradiated WSC by gel permeation chromatography, which showed molecular weights and PDIs of 5.5 KDa and 1.043, 7.5 KDa and 1.07, $7.46 \mathrm{KDa}$ and 1.05 , or $7.17 \mathrm{KDa}$ and 1.047 for WSC, AEMAg-WSC with $5 \mathrm{kGy}$, AEMA-g-WSC with $10 \mathrm{kGy}$, or AEMAg-WSC with $25 \mathrm{kGy}$, respectively. We used AEMA-g-WSC irradiated with $5 \mathrm{kGy}$ for the remaining experiments because dosages $>5 \mathrm{kGy}$ did not enhance the grafting efficiency and because AEMA-g-WSC irradiated with $10 \mathrm{kGy}$ and $25 \mathrm{kGy}$ showed a slight degree of browning (data not shown).

Gamma irradiation is used to induce graft polymerization, where the associated energy uniformly activates the reaction between monomers and chitosan. ${ }^{29}$ Radiation-based graft polymerization causes ionization of chitosan active sites, which initiates reactions with the vinyl groups and side chains of acrylate monomers. ${ }^{29}$ The mechanism for this reaction can be explained by new bond formation between the $-\mathrm{CH}_{2} \mathrm{OH}$ group of WSC and the vinyl group of AEMA, as shown in Figure 1A. Polyplexes formed by electrostatic interaction

A

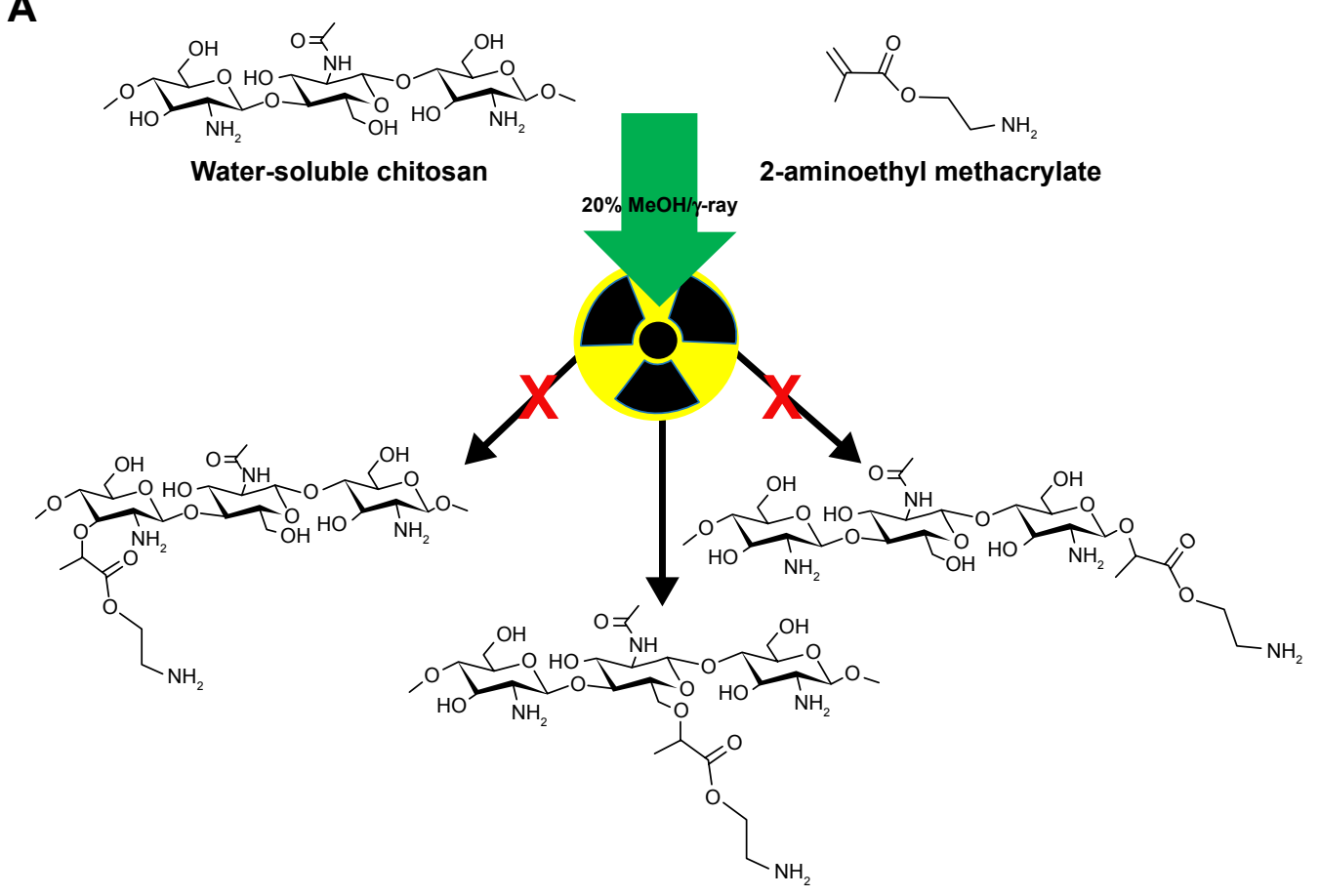

B

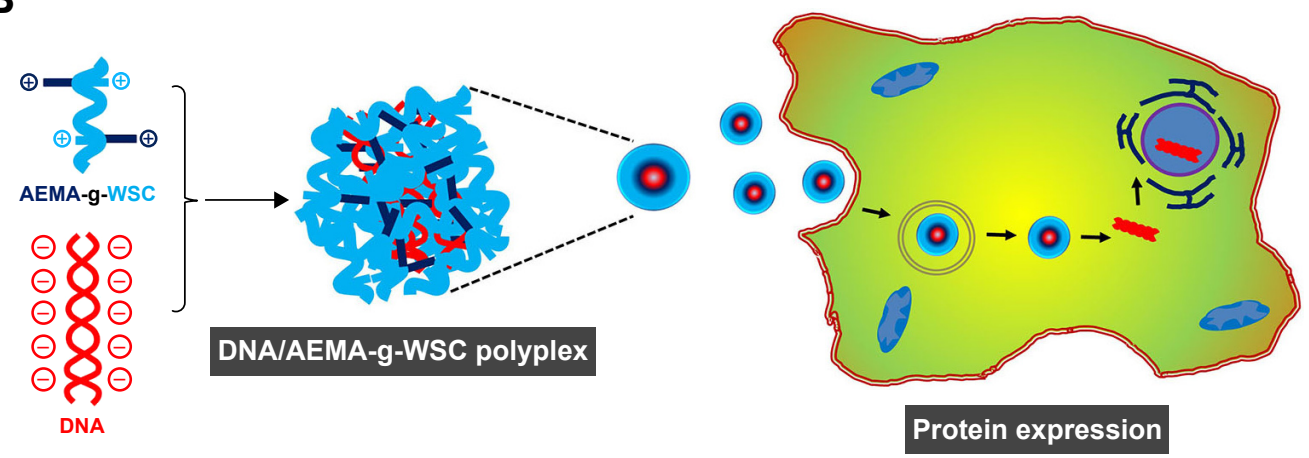

Figure I Schematic representation of AEMA-g-WSC copolymer synthesis by gamma irradiation (A) and illustration of the gene-delivery system (B). Abbreviations: AEMA, 2-aminoethl methacrylate; AEMA-g-WSC, 2-aminoethl methacrylate-grafted water-soluble chitosan; WSC, water-soluble chitosan. 
between DNA and AEMA-g-WSC will be internalized by endocytosis and followed by endosomal escaped via proton sponge effect. Dissociated DNA from polyplexes will be localized into nucleus and processed by protein expression (Figure 1B).

Although gamma irradiation of chitosan has been investigated by many researchers, a detailed analysis of grafting sites of functional biomaterial has not yet been conducted. Figure $2 \mathrm{~A}$ shows ${ }^{1} \mathrm{H}-\mathrm{NMR}$ spectra confirming the structure of AEMA-g-WSC synthesized by gamma irradiation, without initiators. Characteristic peaks for AEMA-g-WSC were classified between 1.3 and $5 \mathrm{ppm}$. In this spectrum, 2 proton peaks corresponding to the farbon atom (Cf) of AEMA at 5.8 and $6.2 \mathrm{ppm}$ disappeared due to breaking of the double bond, but 1 peak appeared at $4.7 \mathrm{ppm}$. These findings indicated that the double bond of AEMA was broken and that a new bond formed between the $-\mathrm{CH}_{2}$ group of AEMA and the $-\mathrm{CH}_{2} \mathrm{OH}$ group of glucosamine.

These results confirmed the successful synthesis of AEMA-grafted WSC by gamma irradiation. Two-dimensional (2D) NMR techniques including 2D ${ }^{1} \mathrm{H}-{ }^{1} \mathrm{H}$ COSY, HSQC, HMBC, TOCSY, and ROESY have been used extensively to elucidate the chemical structures of materials. In particular, the ${ }^{1} \mathrm{H}-{ }^{13} \mathrm{C}$ HSQC method offers the advantage of revealing detailed structures of the carbon atoms associated with each hydrogen atom. Here, using an ${ }^{1} \mathrm{H}-{ }^{13} \mathrm{C}$ HSQC spectrum, we identified the structure of AEMA-g-WSC and found no changes in the chitosan structure, which excluded the possibility that the glucosamine chain was broken by gamma irradiation. The HSQC spectrum (Figure 2B) confirmed that grafted chitosan and AEMA protons correlated with carbon atoms corresponding to each proton. Specifically, the Ca of the methyl group of AEMA (peak at $23 \mathrm{ppm}$ ) was associated with the Ha (peak at $2.8 \mathrm{ppm}$ ). These results confirmed that the synthesis of AEMA-g-WSC by gamma irradiation was achieved without bond breaking in the chitosan molecule.

To develop AEMA-g-WSC as a gene carrier, it is important to assess whether it can form complexes electrostatically with condensed pDNA. Previously, the electrostatic interaction between pDNA (pEGFP-N1) and AEMA, WSC, or AEMA-g-WSC as a function of the pDNA: sample weight ratio was determined by gel electrophoresis retardation. The results in Figure 3A show that AEMA, WSC, and AEMAg-WSC electrostatically neutralized pDNA and abolished its electrophoretic mobility at weight ratios of $1: 8,1: 2$, and 1:0.5, respectively. The gene-binding ability of AEMA-gWSC was higher than that of AEMA and WSC, due to the increased positive charges in the AEMA-g-WSC complex. DLS was used to determine the size distribution and zeta potential of the complexes. The pDNA/AEMA complexes were not observed in all tested weight ratios, suggesting that added AEMA bound to pDNA (as shown in Figure 3A), but did not condense pDNA. This result indicated that the size of pDNA was significantly enlarged because the supercoiled pDNA was unfolded by the AEMA molecules.

As shown in Figure 3B, the particle sizes of pDNA/WSC polyplexes averaged up to $1,200 \mathrm{~nm}$, while those for $\mathrm{pDNA} /$ AEMA-g-WSC polyplexes were 170, 221, and $282 \mathrm{~nm}$ at weight ratios of $1: 4,1: 8$, and $1: 16$, respectively, which are suitable particle sizes for cellular uptake. The zeta potentials of the pDNA polyplexes are shown in Figure 3B. Although the zeta potentials of pDNA/AEMA polyplexes increased dose-dependently, the zeta potentials of all tested complexes were under $-15 \mathrm{mV}$. The pDNA/AEMA-g-WSC polyplexes had the higher zeta potentials, correlating closely with patterns observed in both the electrophoretic-mobility and particle-size results. To ascertain the morphologies of the complexes, the negatively stained samples were observed by performing transmission electron microscopy in a lowdose mode of electron beam. As shown in Figure 3C, pDNA showed irregular structures, WSCs were just bound to pDNA, and $\mathrm{pDNA} / \mathrm{AEMA}-\mathrm{g}-\mathrm{WSC}$ polyplexes formed nanoparticles with a spherical shape and compact structure. The results indicated that AEMA-g-WSC had the ability to bind easily and form nanoparticles with DNA, which is essential for gene uptake into cells.

The in vitro cytotoxicities of AEMA, WSC, and AEMA$\mathrm{g}$-WSC were measured as a function of the sample concentration in CCK and hemolysis assays. The results with L929 and $\mathrm{rRBC}$ cells showed that AEMA reduced cell survival and increased hemolysis with increasing monomer concentrations (Figure 4). In contrast, cells incubated with WSC and AEMA-g-WSC showed $92 \%$ and $95 \%$ viability, respectively, at $0.5 \mathrm{mg} / \mathrm{mL}$. WSC and AEMA-g-WSC induced $1.6 \%$ and $1.1 \%$ hemolysis, respectively, at $0.5 \mathrm{mg} / \mathrm{mL}$. These result indicated that AEMA-g-WSC can potentially serve as a safe gene carrier.

To investigate the gene-delivery efficiency of samples, the cellular uptake and expression of the green fluorescent protein (GFP) plasmid were examined by fluorescence microscopy and flow cytometry. None of the HCT116 cells transfected with the pDNA/AEMA and pDNA/WSC complexes showed green fluorescence, due to their low negative surface charge and condensing ability. However, AEMA-gWSC showed dose-dependent GFP expression and a better transfection efficiency than Lipofectamine (Thermo Fisher Scientific), which was used as a positive control, at up to a 1:6 weight ratio (Figure 5A). FACS analysis of cellular uptake 
A
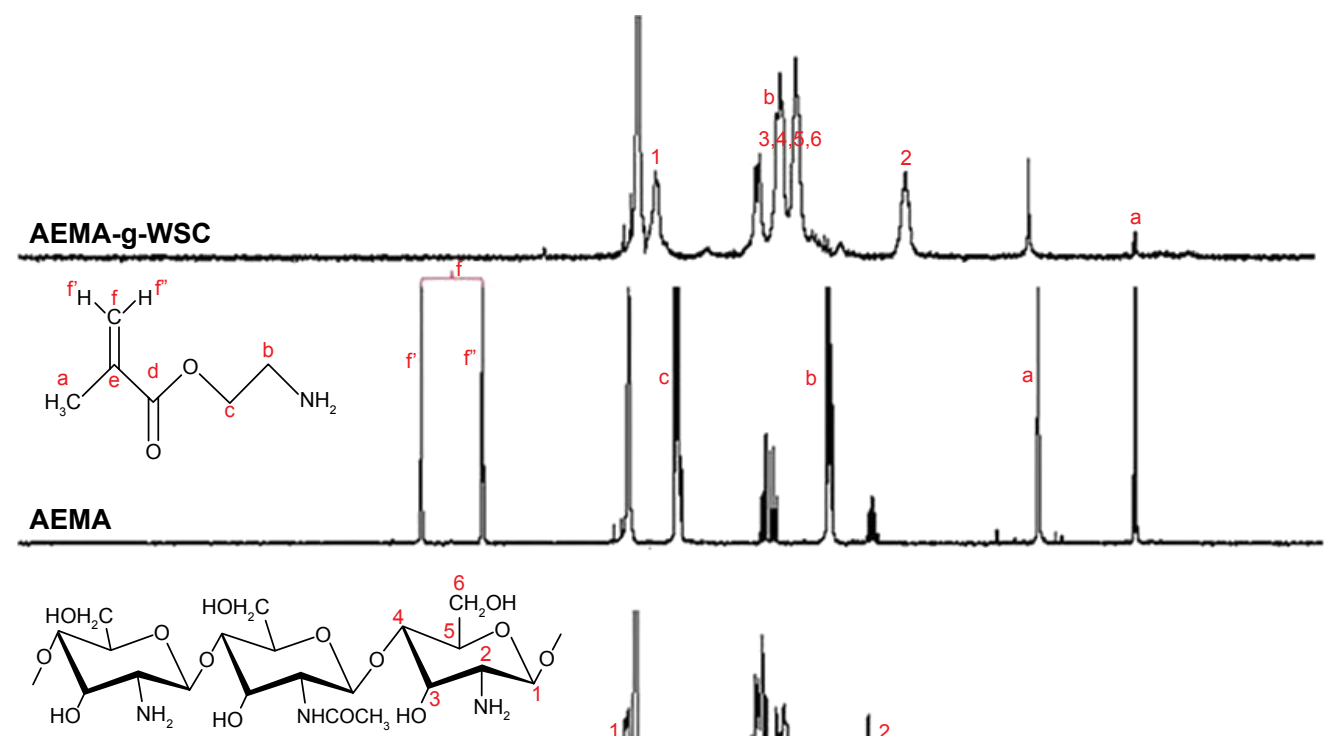

WSC

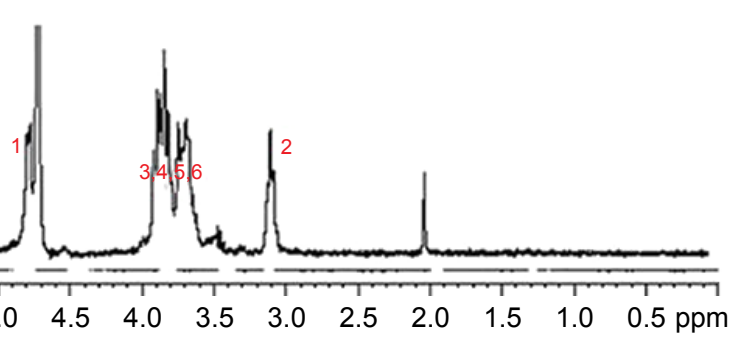

B

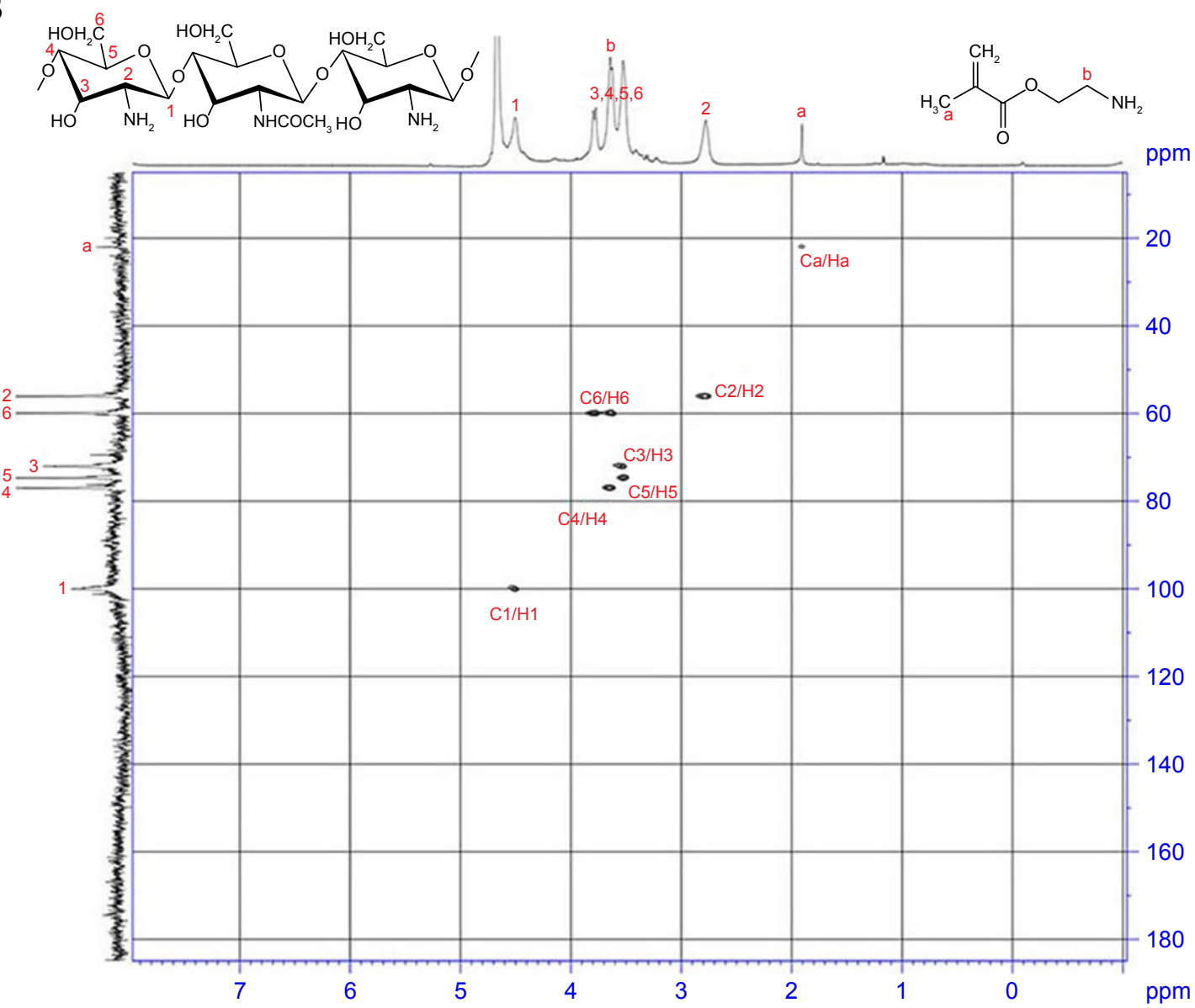

Figure 2 'H-NMR spectra of AEMA, WSC, and AEMA-g-WSC (A) and 2D NMR spectra of AEMA-g-WSC irradiated by 5 kGy gamma irradiation (B).

Abbreviations: 2D NMR, 2-dimensional nuclear magnetic resonance spectroscopy; AEMA, 2-aminoethl methacrylate; AEMA-g-WSC, 2-aminoethl methacrylate-grafted water-soluble chitosan; WSC, water-soluble chitosan. 
A

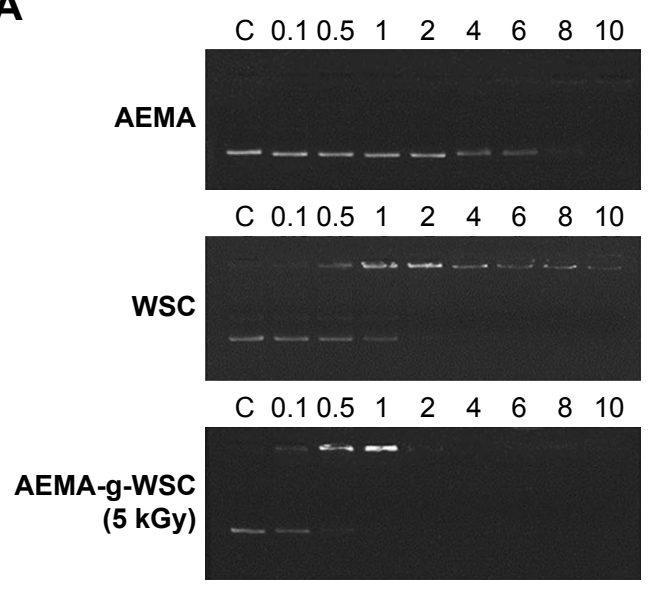

B

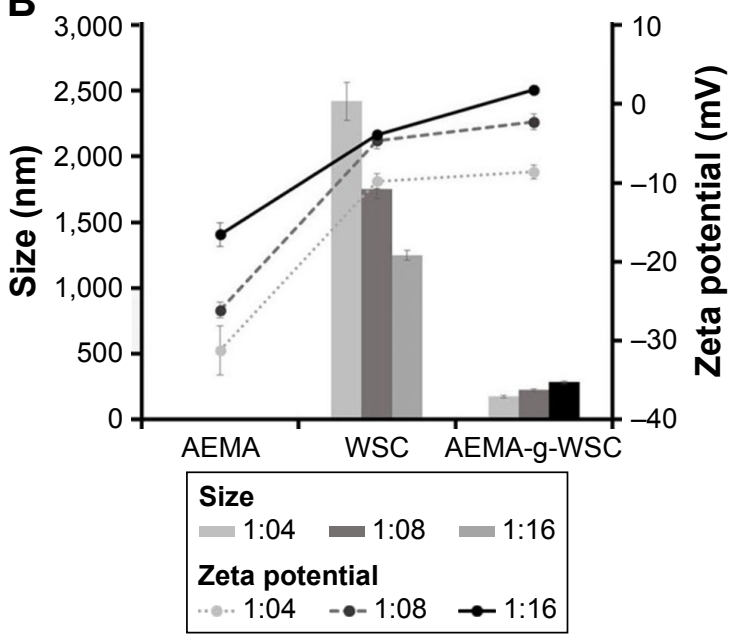

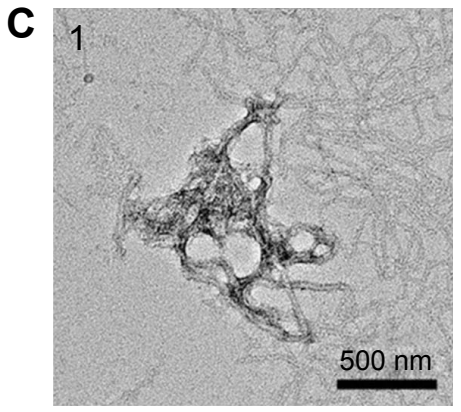
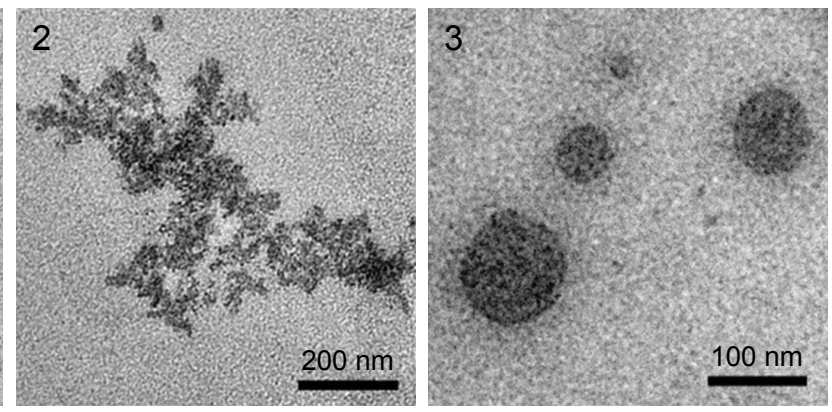

Figure 3 DNA-binding ability of AEMA-g-WSC. (A) DNA-mobility assay results for AEMA, WSC, and AEMA-g-WSC at various weight ratios. (B) Sizes and zeta potentials of pDNA complexes. (C) Electron micrographs observed under TEM. (1) native pDNA. (2) pDNA/WSC at a w/w ratio of I:4. (3) pDNA/AEMA-g-WSC nanoparticles at a $\mathrm{w} / \mathrm{w}$ ratio of I:4.

Abbreviations: AEMA, 2-aminoethl methacrylate; AEMA-g-WSC, 2-aminoethl methacrylate-grafted water-soluble chitosan; WSC, water-soluble chitosan.

of polyplexes with pDNA evaluated showed that the positive control Lipofectamine displayed a cellular uptake efficiency of $43.3 \%$, whereas the cellular uptake in cells exposed to a $1: 2,1: 4,1: 6$, and 1:8 ratio (w/w) of AEMA-g-WSC were 24.1, 28.2, 54.1, and 70.8\%, respectively (Figure 5B). These

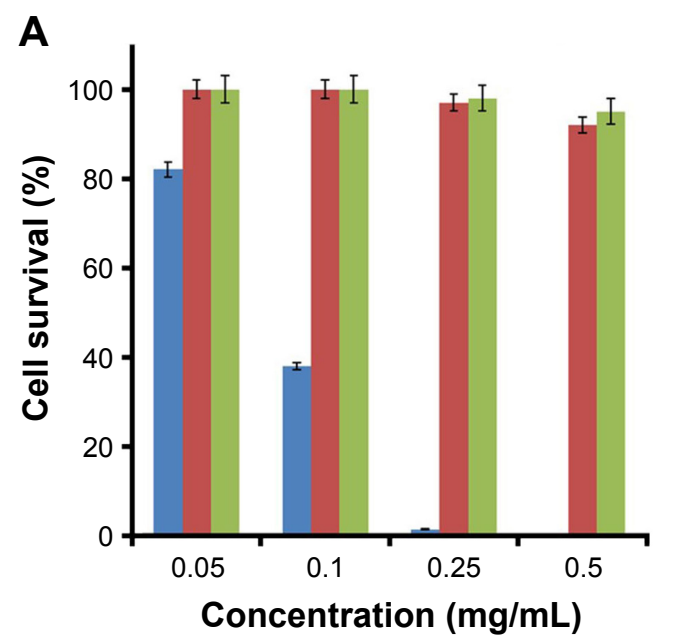

results suggested that the AEMA-g-WSC copolymer is a good candidate for gene delivery.

To ascertain antitumor effects after gene delivery, we used psi-hBCL2 expressing a shRNA against $h B C L 2$. When pDNA was delivered into cells, a shRNA (comprised of

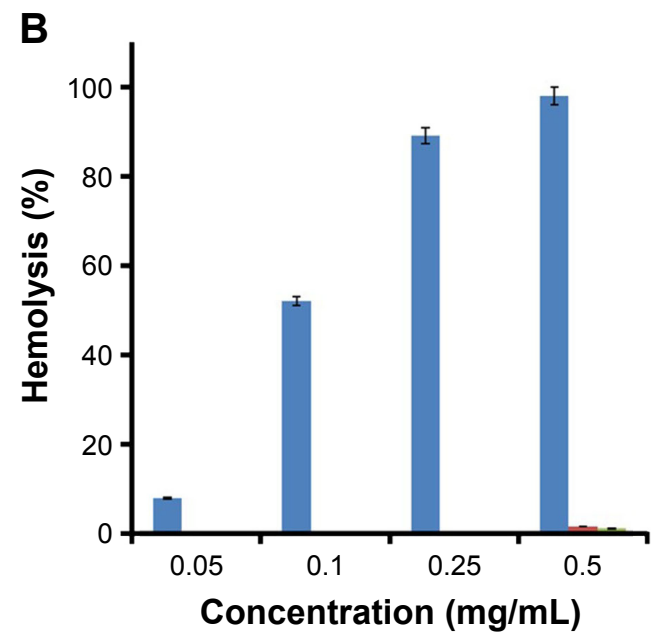

AEMA $\square$ WSC AEMA-g-WSC

Figure 4 In vitro cytotoxic (A) and hemolytic (B) effects of AEMA, WSC, and AEMA-g-WSC in L929 cells and rat erythrocytes, as a function of the sample concentration ( $\mathrm{n}=3$ ). Abbreviations: AEMA, 2-aminoethl methacrylate; AEMA-g-WSC, 2-aminoethl methacrylate-grafted water-soluble chitosan; WSC, water-soluble chitosan. 
A

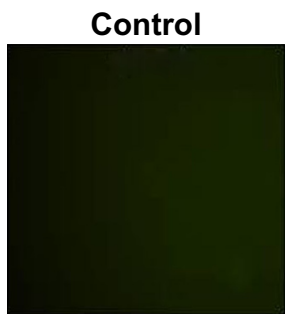

pDNA:

AEMA/1:16
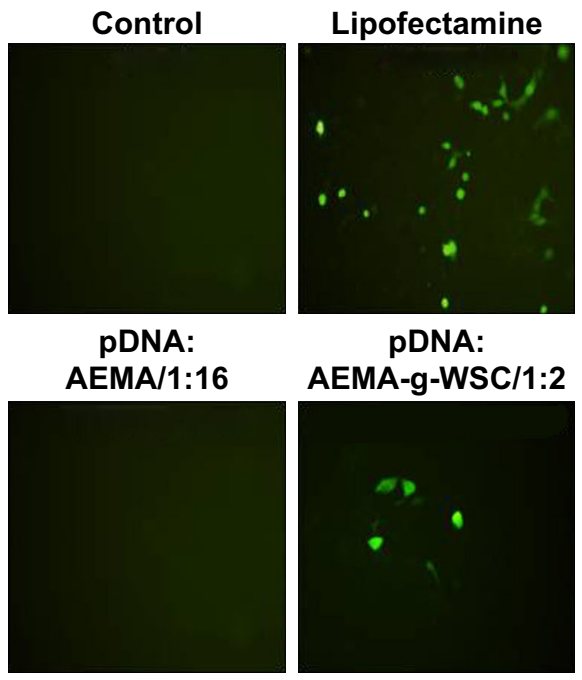

pDNA:

AEMA-g-WSC/1:2

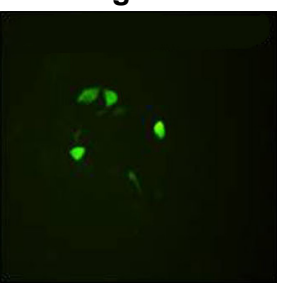

pDNA:

AEMA-g-WSC/1:4

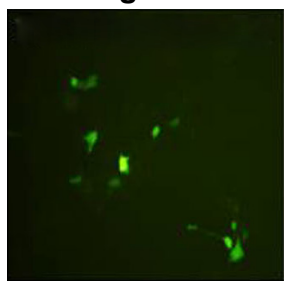

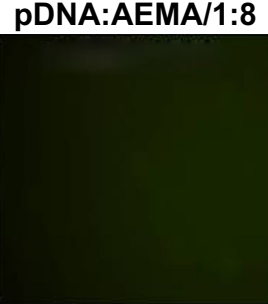

pDNA:

pDNA:WSC/1:16

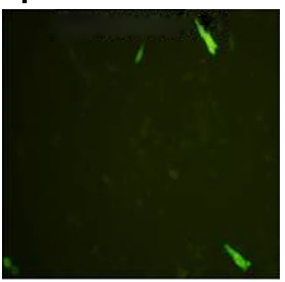

pDNA:

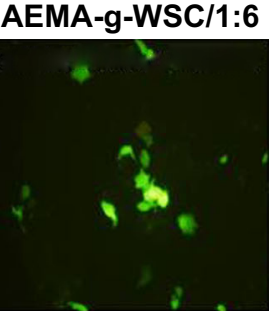

AEMA-g-WSC/1:8

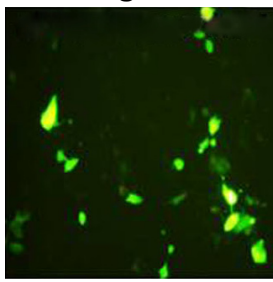

B

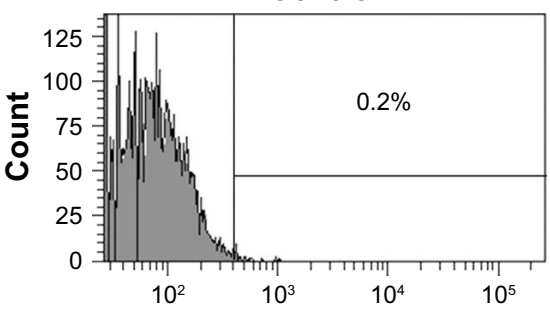

pDNA:AEMA-g-WSC (1:4)

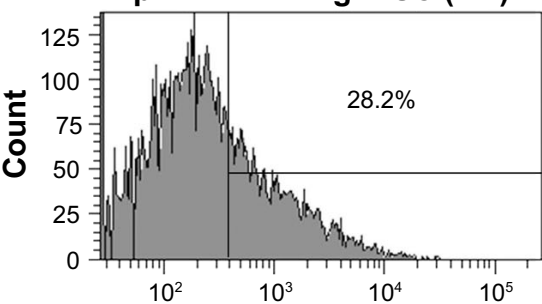

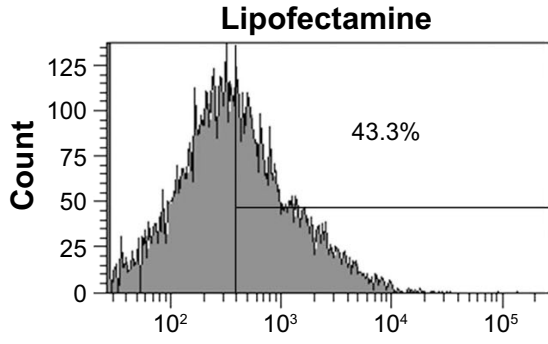

pDNA:AEMA-g-WSC (1:6)

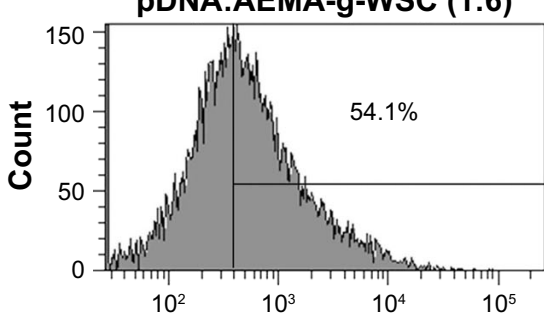

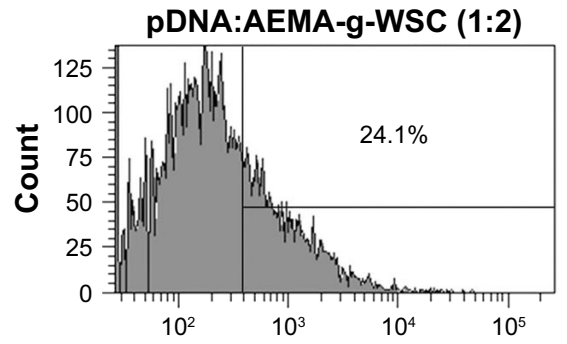

pDNA:AEMA-g-WSC (1:8)

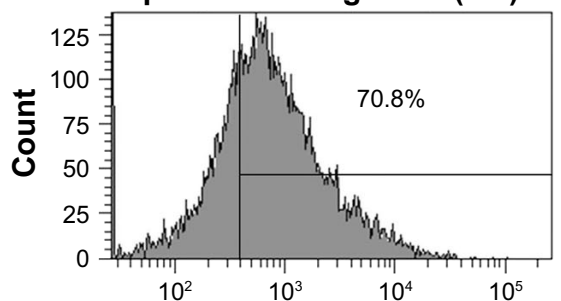

Figure 5 Gene-transfection efficiencies in HCTII 6 cells. (A) Visualization of GFP-expressing cells under a fluorescence microscope. (B) Cellular-uptake efficiency of pDNA complexed with the FNR-675-labeled AEMA-g-WSC copolymer.

Abbreviations: AEMA-g-WSC, 2-aminoethyl methacrylate-grafted water-soluble chitosan; GFP, green fluorescent protein.

an artificial RNA fragment with a tight hairpin turn), was continuously expressed in the nucleus of transfected cells, which offers the advantages of relatively low degradation and turnover, compared with small interfering RNA. $B C L 2$ is an anti-apoptosis gene that can suppress apoptosis in abnormal cells. ${ }^{37,38}$ Therefore, silencing BCL2 mRNA leads to caspase-dependent apoptosis and autophagic cell death. $^{38,39}$

The antitumor activity of polyplexes with psi-hBCL2 was evaluated by a CCK assay in HCT116 cells at various pDNA concentrations and $w / w$ ratios. The psi-hBCL2/WSC polyplexes did not inhibit cell proliferation after treatment at a $1: 32 \mathrm{w} / \mathrm{w}$ ratio (Figure $6 \mathrm{~A}$ ), in agreement with the transfection-efficiency results under the same condition. We did not confirm the antitumor activity of the AEMA monomer due to its high cytotoxicity. AEMA-g-WSC polyplexes with psi-hBCL2 dose-dependently inhibited the proliferation of HCT116 cells, which showed survival rates of $89.1 \%, 68.3 \%$, and $34.7 \%$ using $1 \mu \mathrm{g}$ of psi-hBCL2 at a $1: 2,1: 4$, and $1: 8$ (psihBCL2:AEMA-g-WSC) w/w ratio, respectively (Figure 6A). Moreover, the expression of caspase- 3 , which is activated in apoptotic cells by extrinsic and intrinsic pathways, ${ }^{40}$ was analyzed by immunocytometry (Figure 6B). Although caspase- 3 showed little or no expression in HCT116 cells transfected with psi-BCL2/WSC polyplexes, cells transfected with psiBCL2 using AEMA-g-WSC or the commercial TurboFect reagent (Thermo Fisher Scientific) showed significantly increased caspase- 3 expression.

To investigate in vitro antitumor effect of delivering psi-hBCL2, the apoptosis rates of transfected cells were 


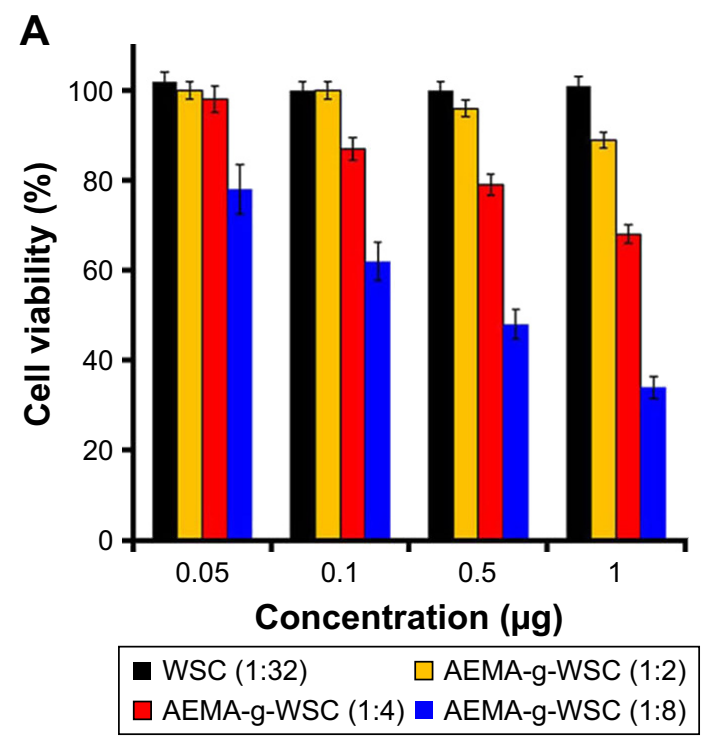

B

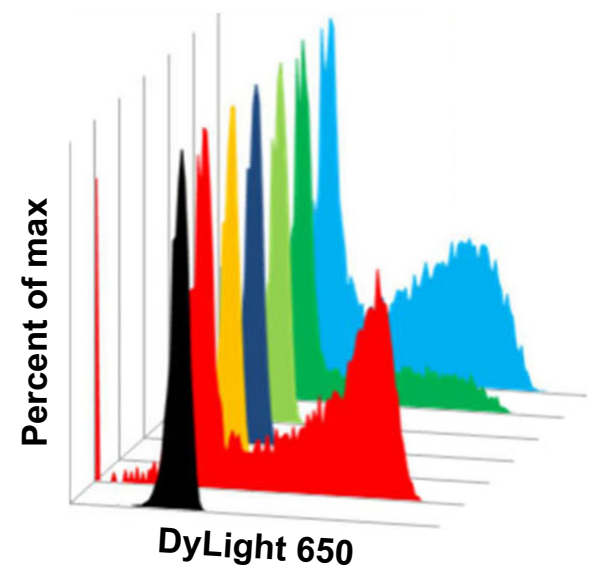

\begin{tabular}{|ll|}
\hline Negative control & TurboFect \\
WSC (1:16) & WSC (1:32) \\
AEMA-g-WSC (1:2) & AEMA-g-WSC (1:4) \\
AEMA-g-WSC (1:8) & \\
\hline
\end{tabular}

C
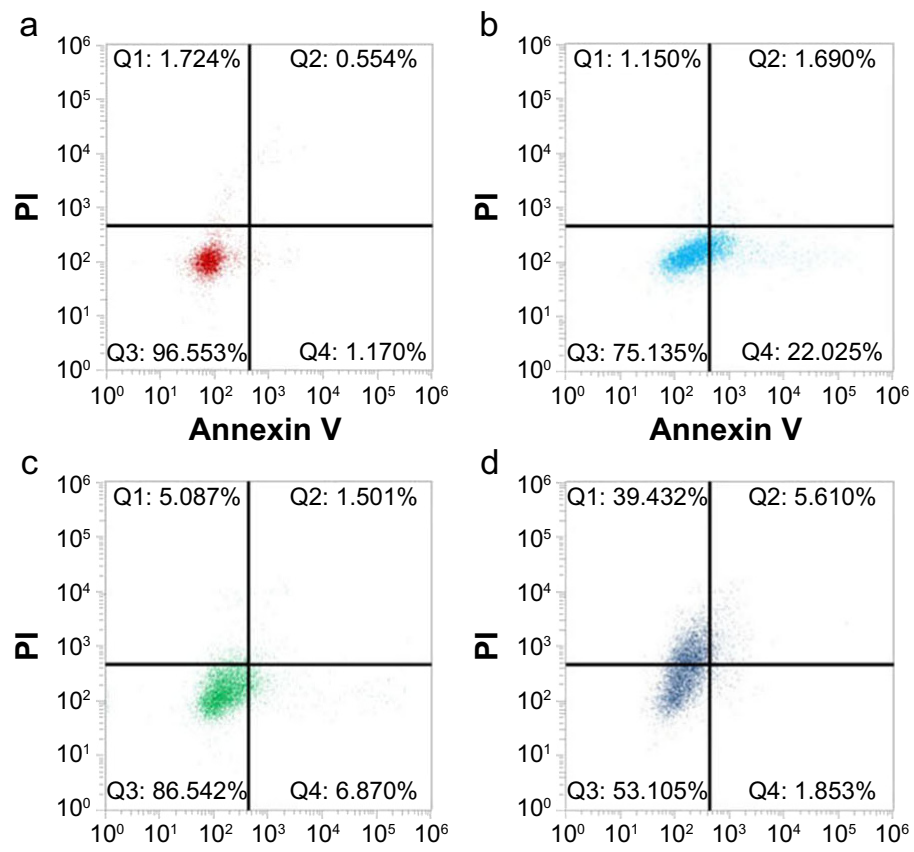

Annexin V

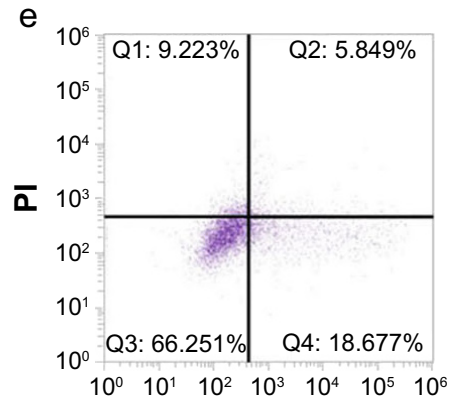

Annexin V

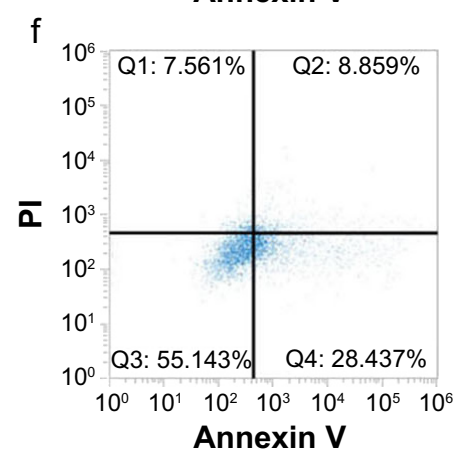

Figure 6 Antitumor activity of psi-hBCL2/polymers in HCTII 6 cells. (A) After complexing psi-hBCL2 (0.05, 0.I, 0.5, or I $\mu$ g) and WSC or AEMA-g-WSC at the indicated $\mathrm{w} / \mathrm{w}$ ratios, polyplexes were incubated with HCTII6 cells for $48 \mathrm{~h}$, after which cell viabilities were measured in CCK assays. (B) After a 48 -h incubation of psi-hBCL2 $(4 \mu \mathrm{g}) /$ WSC or AEMA-g-WSC polyplexes at the indicated w/w ratios, caspase-3 expression was measured by immunocytometry. (C) After a $48-\mathrm{h}$ incubation with the polyplexes, apoptosis was detected by annexin V-PE and PI staining by flow cytometry in HCTI I6 cells (a) control, (b) TurboFect, (c) WSC (I:32, w/w), (d) AEMA (I:I6, w/w), (e) AEMA-g-WSC (I:4, w/w), (f) AEMA-g-WSC (I:8, w/w).

Abbreviations: AEMA-g-WSC, 2-aminoethyl methacrylate-grafted water-soluble chitosan; CCK, cell counting kit-8; PE, phycoerythrin; PI, propidium iodide.

analyzed by annexin V-phycoerythrin and propidium iodide staining using flow cytometry. As shown in Figure 6C, psi-hBCL2 transfected with TurboFect or WSC (1:32 ratio, w/w) demonstrated apoptosis rates of $23.7 \%$ and $8.4 \%$, respectively, compared with the $1.7 \%$ apoptosis rate of control cells. Transfection of psi-hBCL2 with AEMA showed higher necrosis $(39.4 \%)$ than apoptosis $(7.5 \%)$. Remarkably, psi-hBCL2 transfection with AEMA-gWSC at a 1:4 or 1:8 ratio (w/w) showed higher apoptosis rates $(24.5 \%$ and $37.3 \%$, respectively) than observed with other transfection protocols. These results suggested that
AEMA-g-WSC could efficiently deliver psi-hBCL2 to the cytoplasm of tumor cells and effectively inhibit BCL2 RNA and protein expression following fast endosomal escape by a proton-sponge effect and ready dissociation between the polymer and pDNA.

As shown in Figure 7A, psi-hBCL2/WSC polyplexes could not inhibit tumor growth as compared with control mice (PBS-treated tumor-bearing mice); however, tumor growth was dramatically inhibited in tumor-bearing mice treated with psi-BCL2/AEMA-g-WSC polyplexes. Figure 7B shows the morphological alteration of tumor tissues observed by H\&E 
A

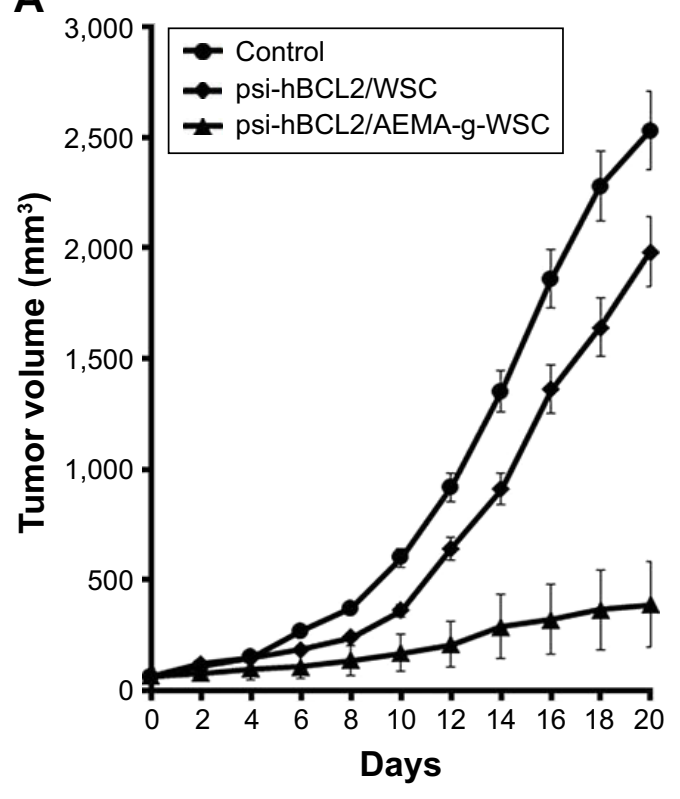

C
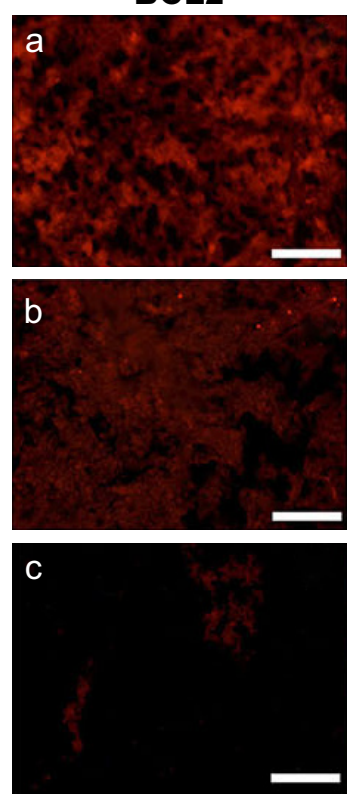

AIF
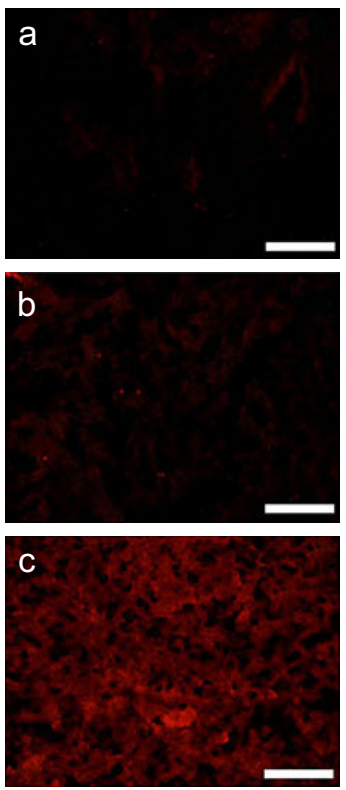

B
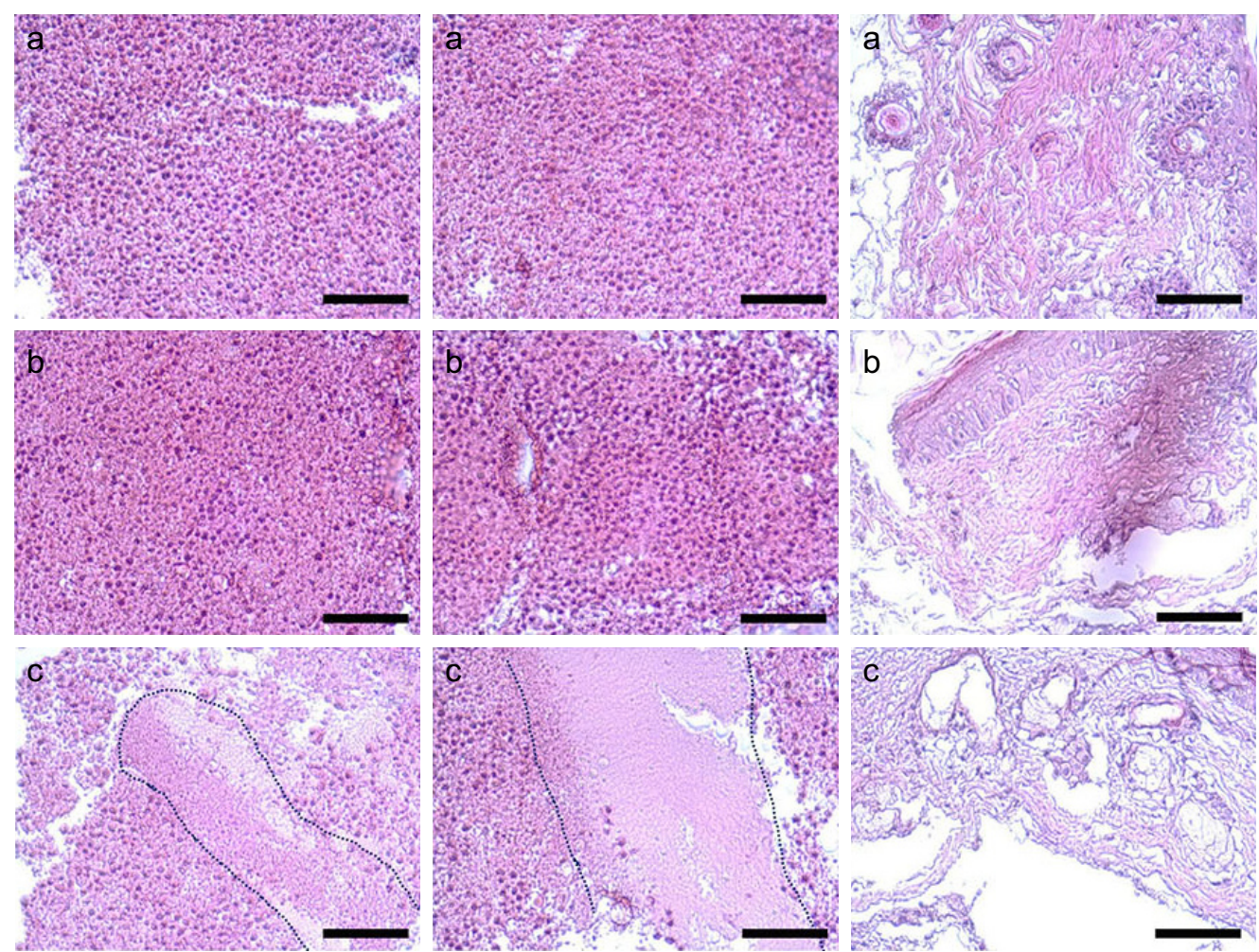

Figure 7 In vivo antitumor activity of psi-hBCL2/AEMA-g-WSC complexes. (A) Distribution of tumor volumes after injection of psi-hBCL2/WSC at a I:64 w/w ratio or psi-hBCL2/AEMA-g-WSC at a 1:8 w/w ratio. (B) H\&E histological analysis of harvested tumors ( $\times 200$ ): (a) control, (b) psi-hBCL2/WSC, (c) psi-hBCL2/AEMA-gWSC. (C) Immunohistochemical analysis of harvested tumors with anti-BCL2 and anti-caspase-3 monoclonal antibodies: (a) control, (b) psi-hBCL2/WSC, (c) psi-hBCL2/ AEMA-g-WSC.

Abbreviation: AEMA-g-WSC, 2-aminoethyl methacrylate-grafted water-soluble chitosan.

staining. Compared with tumor tissues of control mice, no histopathological changes were detected after tumor-bearing mice were treated with psi-hBCL2/WSC polyplexes. Tumor tissues from psi-BCL2/AEMA-g-WSC polyplex-treated, tumor-bearing mice showed a reduction of tumor cells, necrosis, and immune cell infiltration. Furthermore, BCL2 and caspase-3 protein expression in tumor tissues was investigated by immunohistochemical staining with monoclonal antibodies (Figure 7C). Compared with control and psi-hBCL2/WSC polyplex treatments, tumor tissues treated 
with psi-BCL2/AEMA-g-WSC polyplexes showed significantly inhibited BCL2 expression significantly increased caspase- 3 expression. These results demonstrated that the inhibition of tumor growth was due to the increased caspase-3 protein expression after silencing $B C L 2$ mRNA.

\section{Conclusion}

Radiation-based crosslinking or chitosan grafting are among the most promising methods for developing drugdelivery systems in the medical field because they are thought to be safe and efficient. In this study, we developed a graft-polymerization method using gamma irradiation without catalysts and photoinitiators. In addition, this study was the first to determine the exact reaction site of the grafting molecule on chitosan. Gel retardation, particle size, and zeta-potential measurements, as well as TEM images revealed an effective gene-binding capacity of the AEMA-g-WSC copolymer. Furthermore, in vitro and in vivo antitumor effects occurring via $B C L 2$ mRNA silencing and apoptosis induction demonstrated the feasibility of AEMA-g-WSC as a nontoxic gene carrier, although further optimization of the manufacturing process is necessary for cost reduction.

\section{Acknowledgments}

This research was supported by the National Nuclear R\&D Program through the National Research Foundation of Korea (NRF) funded by the Ministry of Science, ICT, and Future Planning, Korea (2017M2A2A6A02018535), and the Basic Science Research Program through the NRF (NRF2017R1A2B4010831).

\section{Author contributions}

All authors contributed toward data analysis, drafting and revising the paper and agree to be accountable for all aspects of the work.

\section{Disclosure}

The authors report no conflicts of interest in this work.

\section{References}

1. Muanprasat $\mathrm{C}$, Chatsudthipong V. Chitosan oligosaccharide: biological activities and potential therapeutic applications. Pharmacol Ther. 2017;170:80-97.

2. Wang J, Wang L, Yu H, et al. Recent progress on synthesis, property and application of modified chitosan: an overview. Int J Biol Macromol. 2016;88:333-344.

3. Islam MA, Firdous J, Choi Y-J, Yun C-H, Cho C-S. Design and application of chitosan microspheres as oral and nasal vaccine carriers: an updated review. Int J Nanomedicine. 2012;7:6077-6093.
4. Azuma K, Izumi R, Osaki T, et al. Chitin, chitosan, and its derivatives for wound healing: old and new materials. J Funct Biomater. 2015;6(1): 104-142.

5. Yang TL. Chitin-based materials in tissue engineering: applications in soft tissue and epithelial organ. Int J Mol Sci. 2011;12(3):1936-1963.

6. Yong SK, Shrivastava M, Srivastava P, Kunhikrishnan A, Bolan N. Environmental applications of chitosan and its derivatives. Rev Environ Contam Toxicol. 2015;233:1-43.

7. Vakili M, Rafatullah M, Salamatinia B, et al. Application of chitosan and its derivatives as adsorbents for dye removal from water and wastewater: a review. Carbohydr Polym. 2014;113:115-130.

8. Philibert T, Lee BH, Fabien NC. Current status and new perspectives on chitin and chitosan as functional biopolymers. Appl Biochem Biotechnol. 2017;181(4):1314-1337.

9. Ragelle H, Vandermeulen G, Préat V. Chitosan-based siRNA delivery systems. J Control Release. 2013;172(1):207-218.

10. Zhang X, Yang X, Ji J, Lui A, Zhai G. Tumor targeting strategies for chitosan-based nanoparticles. Colloids Surf B Biointerfaces. 2016; 148:460-473.

11. Buschmann MD, Merzouki A, Lavertu M, Jean M, Darras V. Chitosans for delivery of nucleic acids. Adv Drug Deliv Rev. 2013;65(9): 1234-1270.

12. Li L, Wei Y, Gong C. Polymeric nanocarriers for non-viral gene delivery. J Biomed Nanotechnol. 2015;11(5):739-770.

13. Tamboli V, Mishra GP, Mitrat AK. Polymeric vectors for ocular gene delivery. Ther Deliv. 2011;2(4):523-536.

14. Yasen W, Dong R, Zhou L, et al. Synthesis of a cationic supramolecular block copolymer with covalent and noncovalent polymer blocks for gene delivery. ACS Appl Mater Interfaces. 2017;9(10):9006-9014.

15. Lacroix M, Khan R, Senna M, Sharmin N, Salmieri S, Safrany A. Radiation grafting on natural films. Radiat Phys Chem. 2014;94:88-92.

16. Stoleru E, Zaharescu T, Hitruc EG, et al. Lactoferrin-immobilized surfaces onto functionalized PLA assisted by the gamma-rays and nitrogen plasma to create materials with multifunctional properties. ACS Appl Mater Interfaces. 2016;8(46):31902-31915.

17. Casimiro MH, Gil MH, Leal JP. Suitability of gamma irradiated chitosan based membranes as matrix in drug release system. Int $J$ Pharm. 2010;395(1-2):142-146.

18. Chen Z, Du T, Tang X, et al. Comparison of the properties of collagenchitosan scaffolds after $\gamma$-ray irradiation and carbodiimide cross-linking. J Biomater Sci Polym Ed. 2016;27(10):937-953.

19. Torres MG, Muñoz SV, Solís Rosales SG, et al. Radiation-induced graft polymerization of chitosan onto poly(3-hydroxybutyrate). Carbohydr Polym. 2015;133:482-492.

20. Zhou Y, Dong P, Wei Y, Qian J, Hua D. Synthesis of poly(sulfobetaine methacrylate)-grafted chitosan under $\gamma$-ray irradiation for alamethicin assembly. Colloids Surf B Biointerfaces. 2015;132:132-137.

21. Pino-Ramos VH, Ramos-Ballesteros A, López-Saucedo F, et al. Radiation grafting for the functionalization and development of smart polymeric materials. Top Curr Chem (Cham). 2016;374(5):63.

22. Abeer MM, Amin MC, Lazim AM, et al. Synthesis of a novel acrylated abietic acid-g-bacterial cellulose hydrogel by gamma irradiation. Carbohydr Polym. 2014;110:505-512.

23. Badhe RV, Nanda RK, Chejara DR, et al. Microwave-assisted facile synthesis of a new tri-block chitosan conjugate with improved mucoadhesion. Carbohydr Polym. 2015;130:213-221.

24. Zhenlin X, Youhui Y, Yueming J, et al. Synthesis and characterization of konjac glucomannan-graft-polyacrylamide via $\gamma$-irradiation. Molecules. 2008;13(3):490-500.

25. World Health Organization (WHO). High-dose irradiation: wholesomeness of food irradiated with doses above $10 \mathrm{kGy}$. Report of a Joint FAO/ IAEA/WHO Study Group, Technical Report Series N_890. Geneva, Switzerland: WHO; 1999

26. Chmielewski AG. Chitosan and radiation chemistry. Radiat Phys Chem. 2010;79:272-285.

27. Yilmaz E, Adali T, Yilmaz O, et al. Grafting of poly(triethylene glycol dimethacrylate) onto chitosan by ceric ion initiation. React Funct Polym. 2007;67:10-18. 
28. Yu L, Liu L, Wei'an Z, et al. A new hybrid nanocomposite prepared by graft copolymerization of butyl acrylate onto chitosan in the presence of organophilic montmorillonite. Radiat Phys Chem. 2004;69(6): $467-471$.

29. Casimiro MH, Botelho ML, Leal JP, Gil MH. Study on chemical, UV and gamma radiation-induced grafting of 2-hydroxyethyl methacrylate onto chitosan. Radiat Phys Chem. 2005;72(6):731-735.

30. Nah JW, Jang MK. Spectroscopic characterization and preparation of low molecular, water-soluble chitosan with free-amine group by novel method. J Polym Sci Part A Polym Chem. 2002;40:3796-3803.

31. Bao X, Wang W, Wang C, et al. A chitosan-graft-PEI-candesartan conjugate for targeted co-delivery of drug and gene in anti-angiogenesis cancer therapy. Biomaterials. 2014;35(29):8450-8466.

32. Lu H, Dai Y, Lv L, Zhao H, He X. Chitosan-graft-polyethylenimine/ DNA nanoparticles as novel non-viral gene delivery vectors targeting osteoarthritis. PLoS One. 2014;9(1):e84703.

33. Park SC, Nam JP, Kim YM, Kim JH, Nah JW, Jang MK. Branched polyethylenimine-grafted-carboxymethyl chitosan copolymer enhances the delivery of pDNA or siRNA in vitro and in vivo. Int J Nanomedicine. 2013;8:3663-3677.
34. Tang S, Huang Z, Zhang H, Wang Y,HuQ, Jiang H. Design and formulation of trimethylated chitosan-graft-poly( $\varepsilon$-caprolactone) nanoparticles used for gene delivery. Carbohydr Polym. 2014;101:104-112.

35. Yue W. Prevention of browning of depolymerized chitosan obtained by gamma irradiation. Carbohydr Polym. 2014;101:857-863.

36. Shen K, Hu Q, Wang Z, Qu J. Effect of ${ }^{60} \mathrm{Co}$ irradiation on the properties of chitosan rod. Mater Sci Eng C. 2011;31:866-872.

37. Ashkenazi A, Fairbrother WJ, Leverson JD, Souers JA. From basic apoptosis discoveries to advanced selective BCL-2 family inhibitors. Nat Rev Drug Discov. 2017;16(4):273-284.

38. Croce CM, Reed JC. Finally, an apoptosis-targeting therapeutic for cancer. Cancer Res. 2016;76(20):5914-5920.

39. Cai RQ, Liu DZ, Cui H, et al. Charge reversible calcium phosphate lipid hybrid nanoparticle for siRNA delivery. Oncotarget. 2017;8(26): $42772-42788$

40. Horwacik I, Rokita H. Targeting of tumor-associated gangliosides with antibodies affects signaling pathways and leads to cell death including apoptosis. Apoptosis. 2015;20(5):679-688.
International Journal of Nanomedicine

\section{Publish your work in this journal}

The International Journal of Nanomedicine is an international, peerreviewed journal focusing on the application of nanotechnology in diagnostics, therapeutics, and drug delivery systems throughout the biomedical field. This journal is indexed on PubMed Central, MedLine, CAS, SciSearch ${ }^{\circledR}$, Current Contents ${ }^{\circledR} /$ Clinical Medicine,

\section{Dovepress}

Journal Citation Reports/Science Edition, EMBase, Scopus and the Elsevier Bibliographic databases. The manuscript management system is completely online and includes a very quick and fair peer-review system, which is all easy to use. Visit http://www.dovepress.com/ testimonials.php to read real quotes from published authors. 